\title{
Total hip arthroplasty following arthrodesis: a single-center experience of 17 patients
}

This article was published in the following Dove Press journal:

Therapeutics and Clinical Risk Management

\author{
Murat Çalbıyık \\ Department of Orthopedics and \\ Traumatology, Hitit University, Faculty \\ of Medicine, Corum, Turkey
}

Purpose: We aimed to present our experience with total hip arthroplasty in patients with previous hip arthrodesis.

Patients and methods: This was a retrospective study, in which clinical and radiological outcomes of total hip arthroplasty performed in 17 patients (mean age $54.2 \pm 8.5$ years; age range 33-68 years; female to male ratio 10/7) with previous arthrodesis in our clinic between 2001 and 2014 were reviewed. Patients were followed up for 6.7 \pm 2.8 years (range 3-12 years) after the operation and evaluated for ipsilateral knee pain, range of motion, walking capacity, and leg-length discrepancy. The clinical outcome was assessed by the Harris Hip Score.

Results: The outcome of arthroplasty was good or excellent in 14 of 17 patients (82.3\%), fair in two patients $(11.8 \%)$, and failure in one patient (5.9\%). The Harris Hip Score increased to $79.8 \pm 9.8$ postoperatively from a preoperative score of $40.9 \pm 10.1(p<0.01)$. Pain-free hip was obtained in 15 patients $(88.2 \%)$, and range of motion was $88^{\circ}$. Fourteen patients $(82.4 \%)$ reported a significant decrease in back pain, and 11 patients $(64.7 \%)$ in ipsilateral knee pain. Ten patients $(58.8 \%)$ were able to walk normally, five patients $(29.4 \%)$ walked with slight Trendelenburg gait without support, and two patients (11.8\%) with severe Trendelenburg gait using arm rests. The mean leg-length discrepancy was $1.1 \mathrm{~cm}$ (range $0-3 \mathrm{~cm}$ ). The complications were peroneal nerve palsy $(n=3)$, superficial wound infection $(n=3)$, hip dislocation $(n=2)$, and heterotopic ossification $(\mathrm{n}=3)$.

Conclusion: If it is well planned, conversion of hip arthrodesis to total hip arthroplasty is a successful and safe procedure, which increases patients' functionality.

Keywords: hip arthrodesis, total hip arthroplasty, retrospective, range of motion

\section{Introduction}

Spontaneous arthrodesis mostly results from developmental and infectious diseases, ankylosing spondylitis, and trauma. Surgical hip arthrodesis is a reconstruction technique for severe cases of noninflammatory, monoarticular hip arthritis. ${ }^{1}$ Although overall long-term functionality of hip arthrodesis is good, it is frequently associated with disability and low back or ipsilateral knee pain in the long term, which necessitates the conversion to total hip arthroplasty. ${ }^{2,3}$ Furthermore, a mobile and stable hip joint is required to prevent degenerative changes in the adjacent sacroiliac, lumbar spine, and knee joints, and to increase patients' quality of life. Therefore, conversion to total hip arthroplasty is commonly performed in patients with hip arthrodesis. ${ }^{4,5}$ The purpose of the total hip arthroplasty in these patients is to obtain a painless mobile stable hip, to support the long-distance walk without pain, and to provide a painless back and knee.

However, total hip arthroplasty requires a complex and high-risk procedure in cases with arthrodesis. ${ }^{6}$ Although some previous studies reported a very good outcome for
Correspondence: Murat Çalbıyık Department of Orthopedics and Traumatology, Hitit University, Faculty of Medicine, Ulukavak Mahallesi, Çiftlik Çayırı Cd. 45 A, 19040 Corum, Turkey Tel +905327698962

Email drmuratcalbiyik@hotmail.com 
conversion from surgical or spontaneous arthrodesis to total hip arthroplasty, ${ }^{7,8}$ it is still a challenging procedure due to atropic muscles, prior surgery, or deformed hip anatomy. $3,9,10$ Therefore, a high complication rate mostly due to mechanical failure, infection, and nerve palsy was reported for conversion arthroplasty. ${ }^{3}$ Since many anatomical and neurological factors affect the outcome of conversion from arthrodesis to total hip arthroplasty, comprehensive preoperative assessment and planning is necessary. However, there is still no common consensus on the indication, preoperative assessment, and surgical technique for conversion of hip arthrodesis to total hip arthroplasty.

In this study, we aimed to present our experience with total hip arthroplasty in patients with spontaneous or surgically induced arthrodesis.

\section{Materials and methods Study population and design}

This was a retrospective study, in which clinical and radiological outcomes of total hip arthroplasty performed in 17 patients (mean age 54.2 \pm 8.5 years; age range 33-68 years; female to male ratio 10/7) with previous arthrodesis in our clinic between 2001 and 2014 were reviewed. The hip arthrodesis was the result of a previous surgical procedure in five patients, as two patients developed spontaneous arthrodesis after tuberculous osteomyelitis, seven patients had developmental hip arthrodesis, two patients had sequelae of Perthes disease, and one had post-traumatic osteoarthritis arthrodesis. The mean duration from hip arthrodesis to total hip arthroplasty was $19.7 \pm 7.51$ years.

The study protocol was approved by the Hitit University Institutional Ethics Committee. Patients or their legal representatives were informed about the surgical procedure and gave written consent before the surgery. Given the retrospective design of the study, the requirement for written consent for the patient's medical records to be reviewed was waived by the Ethics Committee. The study was conducted according to the latest version of the Helsinki Declaration, and the confidentiality of the patients' data was preserved.

\section{Preoperative assessment}

Pelvic Xray scans, computed tomography (CT) images of the hip joint, and three-dimensional CT images of the knee joint were obtained preoperatively. The structure of the acetabulum and the leg-length discrepancy were evaluated. Threedimensional CT images could only be obtained for patients operated on after 2009 (Figure 1). Magnetic resonance (MR) imaging was also performed to evaluate the amount of fat degeneration in the muscles around the hip, and the strength of the hip abductor muscles. The abductor muscle viability was assessed by the amount of fatty degeneration in the preoperative MR images, the perioperative muscle viability, and muscle contractibility to the electrical impulses given at low doses. The amount of leg shortness was evaluated on Xray images of lower extremities.

\section{Surgical technique}

The total hip arthroplasty was applied to the right hip in seven patients and the left hip in 10 patients. The operation was performed under epidural anesthesia while the patient was in a lateral decubitus position. Based on the previous surgical incisions, either the lateral or posterior incision was made. Patients who had a previous surgery and lateral surgical incision were operated on through the lateral approach to the hip joint by using the old incision while the patient was in the lateral decubitus position. If there was no history for previous intervention and no incision scar, the patient was operated on through a posterior incision in the lateral decubitus position. The lateral incision was extended to the proximal, and the posterior incision was extended to the
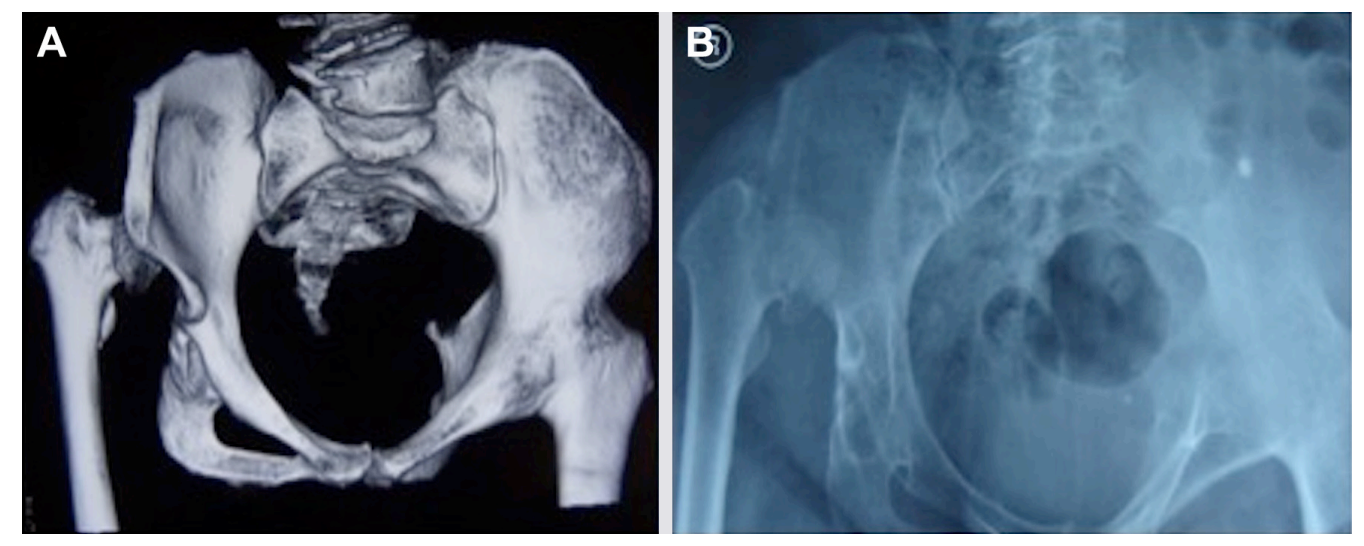

Figure I Three-dimensional computed tomography image (A) and anterior pelvic Xray image (B) of a patient with hip arthrodesis before total hip arthroplasty. 
posterior. Considering the amount of preoperative shortening, external rotator muscles were cut, and fibrotic and thick capsules were removed. Subsequently, a triangulation point in the iliac bone was marked with a $\mathrm{K}$-wire, and its distance to the tip of trochanter major was measured. The fusion site between the femoral neck and the acetabulum was dissected. Femur neck dissection was difficult since rotation movement was limited in hips with arthrodesis. The osteotomy of the femur neck was performed at intervals of $1 \mathrm{~cm}$ under fluoroscopy. The hip joint was mobilized by osteotomizing the femur neck and removing the previously planned bone block under fluoroscopy. The bone block between these two incisions provided sufficient space for free manipulation of the leg on the acetabulum. The acetabulum was localized under fluoroscopy control and the component was placed in the acetabulum rotation center and secured with screws. After the femur was prepared and the femoral stem was placed, the preoperative shortening was compensated by traction, and the appropriate femoral head was placed. The lateral offset femoral component was placed if the abductor muscle strength was weak, and the costrained insert was used in patients who had a risk of dislocation in trial prostheses. If a posterior incision was performed, the sciatic nerve was explored and protected during the surgery. Five patients were implanted with a hip hybrid hip prosthesis, and 12 patients had a cementless hip prosthesis. Seven patients had a constrained acetabular insert, and nine patients had polyethylene inserts. The maximum amount of leg lengthening was $3 \mathrm{~cm}$. In three patients who had over $2.5 \mathrm{~cm}$ lengthening, transient paralysis was observed. In all patients, a drain was placed for $24 \mathrm{~h}$. At the postoperative first day, partial load was given to the joint with assistance. All patients received indomethacin for the first 6 postoperative weeks to prevent heterotopic ossification.

\section{Postoperative follow-up}

Patients were followed up for 6.7 \pm 2.8 years (range 3-12 years) after the operation, and evaluated at the third month, first year, second year, and fifth year for the presence and severity of ipsilateral knee pain, range of motion, walking capacity, and leg-length discrepancy. The clinical outcome of total hip arthroplasty was assessed by the Harris Hip Score, which is a clinician-based outcome measure for hip surgery. ${ }^{11,12}$

\section{Statistical analysis}

The continuous and categorical data were descriptively summarized by mean, standard deviation, range, frequency, and percentages as appropriate. The Wilcoxon signed rank test was used to compare pretreatment and posttreatment total Harris Hip Score. A sample size of 17 achieved 100\% power to detect a mean of paired difference of 38.9 in Harris Hip Score with an estimated standard deviation of 5.0 and a significance level $(\alpha)$ of 0.05 using a two-sided Wilcoxon signed rank test. The level of statistical significance was $p<0.05$.

\section{Results}

According to the total Harris Hip Score, the outcome of total hip arthroplasty was good to excellent in 14 of 17 patients $(82.3 \%)$, fair in two patients $(11.8 \%)$, and failure in one patient (5.9\%). The mean Harris Hip Score increased to 79.8 \pm 9.8 postoperatively from a preoperative score of $40.9 \pm 10.10$ $(p<0.01)$. Radiographic images of patients before and after total hip arthroplasty are given in Figures 2 and 3.
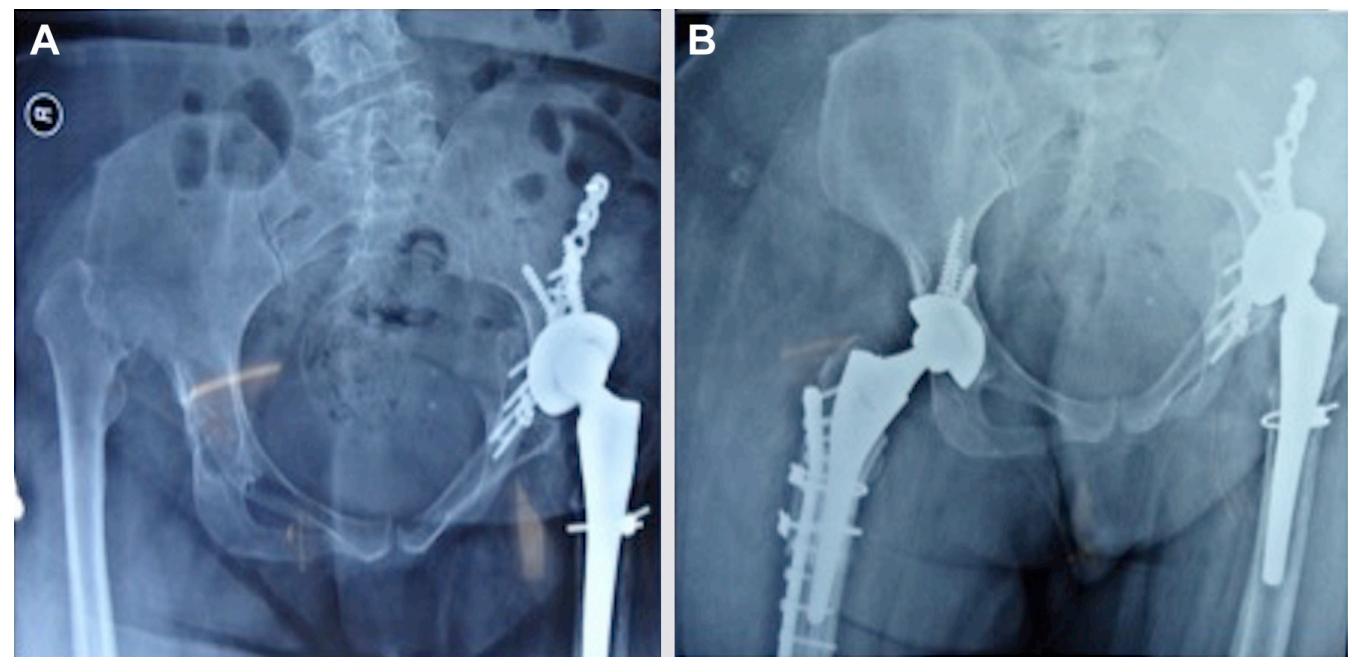

Figure 2 Anterior pelvic Xray images of two patients with hip arthrodesis after left total hip arthroplasty (A) and right total hip arthroplasty (B). 

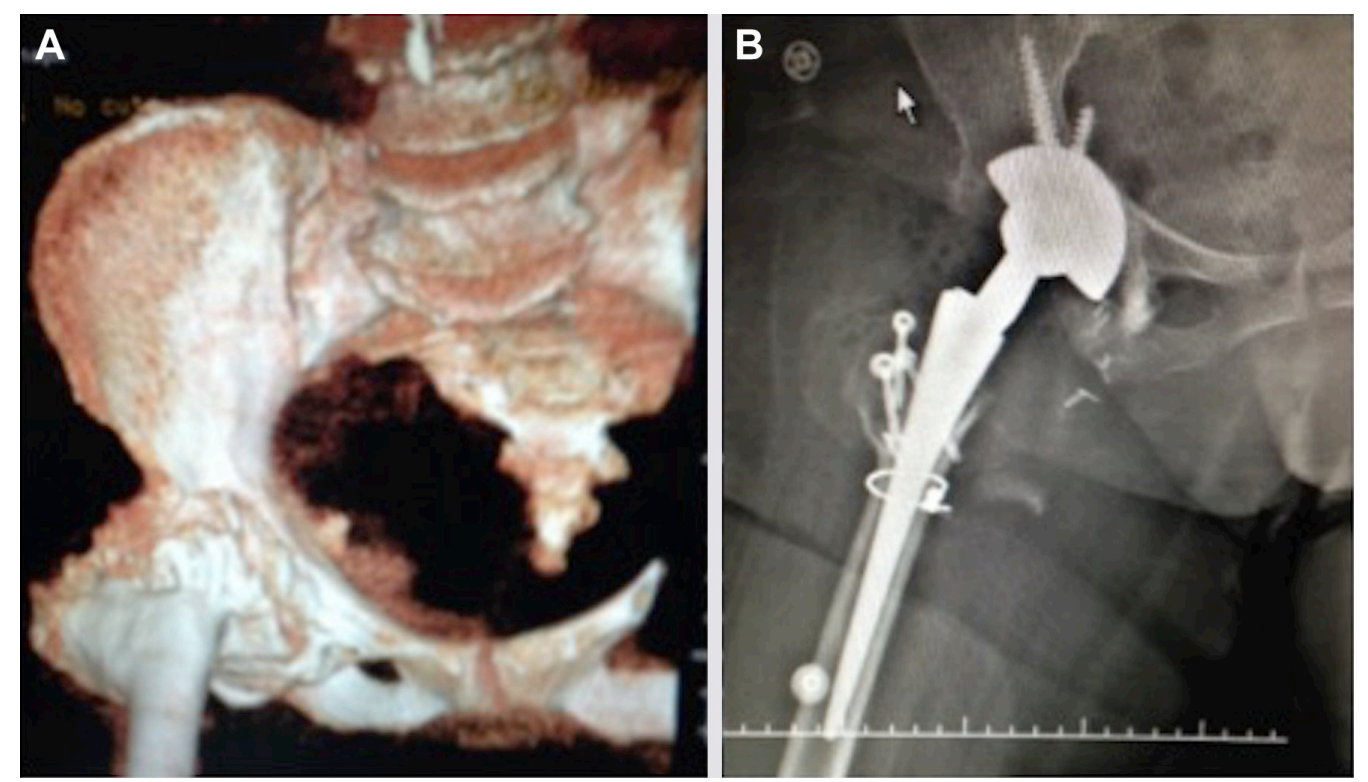

Figure 3 Three-dimensional computed tomography image before right total hip arthroplasty $(\mathbf{A})$ and anterior plane pelvic Xray image after right total hip arthroplasty (B).

In 15 patients (88.2\%), a pain-free hip was obtained and the hip range of motion was $88^{\circ}$ for flexion. Fourteen patients $(82.4 \%)$ reported a significant decrease in back pain, and 11 patients $(64.7 \%)$ reported a decrease in ipsilateral knee pain. Ten patients $(58.8 \%)$ were able to walk normally and five patients (29.4\%) walked with slight Trendelenburg gait

Table I Surgical, clinical, and functional outcome of total hip arthroplasty in the study cohort $(n=17)$

\begin{tabular}{|c|c|}
\hline & $\begin{array}{l}\text { n (\%) or mean } \\
(\min -\max )\end{array}$ \\
\hline \multicolumn{2}{|l|}{ Harris Hip Score } \\
\hline Preoperative & $40.9 \pm 10.1(26-66)$ \\
\hline Postoperative & $79.8 \pm 9.8(58-96)^{*}$ \\
\hline Leg-length discrepancy $(\mathrm{cm})$ & I.I (0-3) \\
\hline Range of motion at hip flexion $\left({ }^{\circ}\right)$ & $83.8 \pm 5.64(70-90)$ \\
\hline $\begin{array}{l}\text { Duration between hip arthrodesis and arthroplasty } \\
\text { (year) }\end{array}$ & $|9.7 \pm 7.5|(9-37)$ \\
\hline \multicolumn{2}{|l|}{ Surgical outcome } \\
\hline Good/excellent & $14(82.3)$ \\
\hline Fair & $2(1 \mid .8)$ \\
\hline Failure & I (5.9) \\
\hline \multicolumn{2}{|l|}{ Decrease or disappearance of pain } \\
\hline Hip pain & $15(88.2)$ \\
\hline Back pain & $14(82.4)$ \\
\hline Knee pain & II (64.7) \\
\hline \multicolumn{2}{|l|}{ Walking } \\
\hline Normal walking without support & $10(58.8)$ \\
\hline Staggered walking without support & $5(29.4)$ \\
\hline Staggered walking with support & $2(11.8)$ \\
\hline
\end{tabular}

Note: $*_{p}<0.01$. Values are presented as mean \pm SD. without support, and two patients (11.8\%) could walk with severe Trendelenburg gait using arm rests. The mean preoperative leg length discrepancy was $2.3 \mathrm{~cm}$ (range $0.8-5.3 \mathrm{~cm}$ ), and it decreased to $1.1 \mathrm{~cm}$ (range $0-3 \mathrm{~mm}$ ) after the operation. The surgical, clinical, and functional outcome of total hip arthroplasty is summarized in Table 1.

Postoperative peroneal nerve palsy was detected in three patients (17.6\%), and superficial wound infection in three other patients (17.6\%). Two patients had hip dislocation at the 6th and 10th weeks postoperatively. They were treated with closed reduction and given a hip abduction brace for 6 weeks. In spite of postoperative indomethacin treatment, three patients (17.6\%) developed heterotopic ossification. The complications of total hip arthroplasty are listed in Table 2.

\section{Discussion}

In this retrospective series of 17 patients, we presented our experience with total arthroplasty of hips with previous arthrodesis and primarily showed that, if well planned,

Table 2 Complications of total hip arthroplasty in the study cohort $(n=17)$

\begin{tabular}{ll}
\hline & $\mathbf{n}(\%)$ \\
\hline Perineal nerve palsy & $3($ I7.6) \\
Superficial wound infection & $3($ I7.6) \\
Hip dislocation & $2(11.8)$ \\
Heterotopic ossification & $3(17.6)$ \\
\hline
\end{tabular}


conversion of hip arthrodesis to total arthroplasty increases functionality of patients and decreases pain.

Hip arthrodesis has been a choice of treatment for young adults with severe arthritis due to the increased rate of failure and multiple revision of total hip arthroplasty in this population. ${ }^{1,2}$ However, in the long term, patients with arthrodesis suffer from back and ipsilateral pain and dysfunctionality, and conversion to total hip arthroplasty becomes compulsory. On the other hand, with the recent improvements in surgical materials and techniques for total hip arthroplasty, the surgical hip arthrodesis is currently not commonly used for the treatment of end-stage hip disease. ${ }^{13}$ But conversion surgery is still frequently performed for patients who had previous arthrodesis.

Conversion of hip arthrodesis to total hip arthroplasty is a challenging procedure with high complication rates compared to primary arthroplasty. ${ }^{14,15}$ The goal of total hip arthroplasty in these patients is to create a mobile and stable hip joint, which depends on the structure of the hip abduction muscles and the leg-length discrepancy. In order to achieve a stable hip, the strength and balance of the muscles around the hip is important. A careful preoperative evaluation and planning should be performed with reference to a normal hip. In addition to the anatomy of the hip and type of arthrodesis, the age of patients and time to conversion surgery have been suggested to affect the outcome of total hip arthroplasty in some studies. ${ }^{4}$ Total hip arthroplasty is reported to be associated with better prognosis and higher hip score in cases of spontaneous hip arthrodesis compared to those with surgical arthrodesis. ${ }^{4}$ Additionally, the higher surgical success is obtained in patients aged 50 years and older and in cases with shorter time since arthrodesis. ${ }^{4}$ In contrast, some studies reported that the time to conversion or type of arthrodesis had no significant correlation with the clinical outcome. ${ }^{16}$ The age of patients in our series ranged from 33 to 68 years, five patients had surgical arthrodesis and the rest had spontaneous arthrodesis.

The previous studies on the outcome of conversion from arthrodesis to total hip arthroplasty revealed controversial results. Fernandez-Fairen et $\mathrm{al}^{8}$ compared the long-term outcomes of conversion to total hip arthroplasty from arthrodesis in 48 patients with primary arthroplasty in 50 patients. They found that in a minimum of 10 -year follow-up, the hip function, health-related quality of life, rate of complications, total hip arthroplasty survival, and patient satisfaction were similar between study groups, concluding that conversion of hip arthrodesis to total hip arthroplasty is a successful and safe procedure. In a recent retrospective series of 40 hips converted to total hip arthroplasty from hip arthrodesis, the clinical outcome was successful with respect to Harris Hip Score without the need for further surgical reconstruction in $93 \%$ of cases. ${ }^{17}$ Villanueva et $\mathrm{al}^{16}$ reported the outcome of 21 patients who underwent conversion and found good to excellent outcome, decreased back pain, and high patient satisfaction in a minimum 3 years of follow-up. On the other hand, some other studies indicated that conversion arthroplasty is associated with poorer clinical outcomes and high complication rates compared to primary total hip arthroplasty. ${ }^{4,18}$ In our series of 17 patients, we followed patients for $6.7 \pm 2.8$ years on average after conversion surgery, and obtained good or excellent outcome and increased Harris Hip Score in the majority of patients. We reached the purpose of surgery by obtaining mobile and pain-free hip in $88.2 \%$ of patients with minimum leg-length discrepancy ranging from 0 to $3 \mathrm{~cm}$, and range of motion of $88^{\circ}$ for flexion, which was similar to the recent series by Flecher et al. ${ }^{19}$ The complications were also limited in number and treatable. We recorded perineal nerve palsy, superficial wound infection, hip dislocation, and heterotopic ossification, as reported in the previous studies ${ }^{8,20}$ Our findings support the studies that report the efficacy and safety of the conversion of hip arthrodesis to total hip arthroplasty.

If it is well planned, total hip arthroplasty in patients with hip arthrodesis results in improved functionality. ${ }^{21,22}$ If the etiology of arthrodesis is infection, it should be effectively treated before the surgery. The morphology of the femur and the strength of the gluteal muscles should be evaluated thoroughly before the arthroplasty.

A direct anterior, lateral, or posterior approach has been used for conversion total hip arthroplasty. ${ }^{5,21}$ We performed the conversion total hip arthroplasty through either the lateral or posterior incision according to the previous surgical incisions.

The main limitation of our study was its small sample size and noncomparative design, which prevents us reaching a more definitive conclusion on the benefits and disadvantages of conversion to total hip arthroplasty from arthrodesis in comparison to primary total hip arthroplasty. The longer follow-up is also required for the assessment of functional outcome of conversion arthroplasty in the long term. Nevertheless, the present study is among the few studies in the literature reporting the outcome of conversion to total hip arthroplasty from arthrodesis. Further comparative, prospective, and longer studies are required to conclude on the outcome of conversion arthroplasty. 


\section{Conclusion}

Total hip arthroplasty in patients with previous hip arthrodesis is a challenging surgery due to changes in anatomical structures around the hip. However, if hip anatomy and prognostic factors are extensively evaluated preoperatively and postsurgical expectations are determined accordingly, conversion of hip arthrodesis to total hip arthroplasty is a successful and safe procedure which increases patients' functionality.

\section{Author contributions}

The author (MÇ) contributed and was solely responsible for conceptualization, methodology, analysis, original draft preparation, review, and editing.

\section{Disclosure}

The author reports no conflicts of interest in this work.

\section{References}

1. Stover MD, Beaulé PE, Matta JM, Mast JW. Hip arthrodesis: a procedure for the new millennium? Clin Orthop Relat Res. 2004;418:126-133.

2. Beaulé PE, Matta JM, Mast JW. Hip arthrodesis: current indications and techniques. J Am Acad Orthop Surg. 2002;10:249-258.

3. Jain S, Giannoudis PV. Arthrodesis of the hip and conversion to total hip arthroplasty: a systematic review. J Arthroplasty. 2013;28:1596-1602.

4. Peterson ED, Nemanich JP, Altenburg A, Cabanela ME. Hip arthroplasty after previous arthrodesis. Clin Orthop Relat Res. 2009;467: 2880-2885.

5. Whitehouse MR, Duncan CP. Conversion of hip fusion to total hip replacement: technique and results. Bone Joint J. 2013;95-B(11 Suppl A): 114-119.

6. Boisgard S, Descamps S, Bouillet B. Complex primary total hip arthroplasty. Orthop Traumatol Surg Res. 2013;99(1 Suppl):S34-S42.

7. Kilgus DJ, Amstutz HC, Wolgin MA, Dorey FJ. Joint replacement for ankylosed hips. J Bone Joint Surg Am. 1990;72:45-54.

8. Fernandez-Fairen M, Murcia-Mazón A, Torres A, Querales V, Murcia A Jr. Is total hip arthroplasty after hip arthrodesis as good as primary arthroplasty? Clin Orthop Relat Res. 2011;469:1971-1983.
9. Joshi AB, Markovic L, Hardinge K, Murphy JC. Conversion of a fused hip to total hip arthroplasty. J Bone Joint Surg Am. 2002;84-A: $1335-1341$.

10. Lubbeke A, Katz JN, Perneger TV, Hoffmeyer P. Primary and revision hip arthroplasty: 5-year outcomes and influence of age and comorbidity. J Rheumatol. 2007;34:394-400.

11. Harris WH. Traumatic arthritis of the hip after dislocation and acetabular fractures: treatment by mold arthroplasty. An end-result study using a new method of result evaluation. J Bone Joint Surg Am. 1969;51: 737-755.

12. Soderman P, Malchau H, Herberts P. Outcome of total hip replacement: a comparison of different measurement methods. Clin Orthop Relat Res. 2001;390:163-172.

13. Panagiotopoulos KP, Robbins GM, Masri BA, Duncan CP. Conversion of hip arthrodesis to total hip arthroplasty. Instr Course Lect. 2001;50: 297-305.

14. Kreder HJ, Williams JI, Jaglal S, Axcell T, Stephen D. A population study in the Province of Ontario of the complications after conversion of hip or knee arthrodesis to total joint replacement. Can J Surg. 1999;42: 433-439.

15. Strathy GM, Fitzgerald RH Jr. Total hip arthroplasty in the ankylosed hip. A ten-year follow-up. J Bone Joint Surg Am. 1988;70:963-996.

16. Villanueva M, Sobrón FB, Parra J, Rojo JM, Chana F, Vaquero J. Conversion of arthrodesis to total hip arthroplasty: clinical outcome, complications, and prognostic factors of 21 consecutive cases. HSS J. 2013;9: 138-144.

17. Celiktas M, Kose O, Turan A, Guler F, Ors C, Togrul E. Conversion of hip fusion to total hip arthroplasty: clinical, radiological outcomes and complications in 40 hips. Arch Orthop Trauma Surg. 2017;137: $119-127$.

18. Richards CJ, Duncan CP. Conversion of hip arthrodesis to total hip arthroplasty: survivorship and clinical outcome. J Arthroplasty. 2011;26: 409-413.

19. Flecher X, Ollivier M, Maman P, Pesenti S, Parratte S, Argenson JN. Long-term results of custom cementless-stem total hip arthroplasty performed in hip fusion. Int Orthop. Epub 2018 Jan 19.

20. Tan SM, Chin PL. Total hip arthroplasty for surgical management of advanced tuberculous hip arthritis: Case report. World J Orthop. 2015; 6:316-321.

21. Oztürkmen Y, Karamehmetoğlu M, Leblebici C, Gökçe A, Caniklioğlu M. Cementless total hip arthroplasty for the management of tuberculosis coxitis. Arch Orthop Trauma Surg. 2010;130:197-203.

22. Tamaki T, Oinuma K, Miura Y, Shiratsuchi H. Total hip arthroplasty through a direct anterior approach for fused hips. Hip Int. 2015;25: $549-552$.
Therapeutics and Clinical Risk Management

\section{Publish your work in this journal}

Therapeutics and Clinical Risk Management is an international, peerreviewed journal of clinical therapeutics and risk management, focusing on concise rapid reporting of clinical studies in all therapeutic areas, outcomes, safety, and programs for the effective, safe, and sustained use of medicines. This journal is indexed on PubMed Central, CAS,

\section{Dovepress}

EMBase, Scopus and the Elsevier Bibliographic databases. The manuscript management system is completely online and includes a very quick and fair peer-review system, which is all easy to use. Visit http://www.dovepress.com/testimonials.php to read real quotes from published authors. 